\title{
Study on the Innovation of College English Teaching
}

\author{
Lijuan Zhang ${ }^{1, a}$ \\ ${ }^{1}$ Xi'an International University, Xi'an, Shaanxi, 710077 \\ a email
}

Keywords: Teaching Reform; College English; Innovative Teaching

\begin{abstract}
With the further strengthening of economic globalization, on the one hand the role of English in international communication is increasingly prominent. Personnel training and as positive for the country all walks of talent platform, the quality of English education in the universities must also keep up with new forms go. So, no exception in college English teaching is made more higher requirements. On the other hand our country in recent years have generally adopted the reform and new teaching ideas in universities, gradually from the traditional examination-oriented education to quality education transformation, therefore, in order to meet the development requirements of the times and the new curriculum teaching requirements, better to catch the global economy of the train, to improve our efficiency and improve classroom teaching quality, innovation and reform on university English imperative. In this paper, college English teaching situation, put forward their views and recommendations on its innovative reforms..
\end{abstract}

\section{Introduction}

Economic globalization has brought merchandise trade globalization, English as a common language very wide range of tools, has become a bridge of communication. China is a major power and high-end learning community learning resources are more concentrated expression in the university. So, the key to college English teaching is to break the traditional mode of teaching theoretical knowledge alone, and fully integrated with advanced facilities of modern technology to innovate on teaching [1]. In addition to the practical value of English society reflects its international trend, college English teaching methods are also slowly into line with the international trend. This is something we can be increased through the introduction of foreign teachers, students and other students communicative phenomena see. To university English "face-lift", we must first identify problems and then targeted innovation.

\section{The Main Disadvantages of College English Teaching}

Throughout our passage college English teaching mode, you will find a long time, as compared with the other stages of primary and secondary school English teaching model, the general pattern of college English teaching seems to be no big difference. Primary English knowledge systems more specific and complicated, especially at the more detailed, so the test is often used to test students 'mastery of knowledge, learning, relatively less attention to students' oral expression and communication use. Therefore, they are teaching, in a word: teaching indoctrination, or "dumb English." In this case, the students just passively around the students in class, do not grasp or digest the contents of textbooks, coupled with restrictions by the environmental resources, students do not use knowledge of English consciousness learned in real life, ignoring the practice in this area experience. Hands-on power and the ability to practice theory is very lacking. To sum up mainly caused by the following factors.

The first is the content of education and social needs of the University there is a disconnect. This is mainly manifested in the backward knowledge systems, and some books College has not timely updates, no teaching materials for the needs of the community, the other university teachers of the era of information is not updated in a timely manner to grasp the philosophy of education are somewhat obsolete, He has not changed. So it is easy to cause some students out of school after the practical use of knowledge to keep up with the need to accept the content or obsolete or not in detail. 
And did not learn English plate Obvious division, such as translation, speaking, writing, reading, etc. are mixed together to form a comprehensive curriculum. Followed by the affected long-term oriented education, teaching positioning is not accurate, not combined with the reality of the situation, an exclusive focus on forty-six exam to get a degree or certificate, PubMed, etc., in the content only expand the extension of high school English, usually nor cooperation and practice students have special requirements, ignoring the students' communicative competence in English. Finally, college English class set unreasonable, although a more concentrated period of time to learn English, but overall college English class generally relatively small, uneven student basis, so that the system is just not enough time to learn down. Can not meet the learning needs of students, naturally, do not help students learning English enthusiasm to develop.

The traditional concept of teachers are defined: preaching Tuition FAQ. With the changing times, the functions and competence standards of teachers will naturally be updated. Today, university educators should also bear inspire students to actively to society, and to learn effective conversion of capital to create value for society's consciousness. However, some university teachers not initially set the target application Talents, directly influence the choice of the latter part of the teaching objectives and teaching methods. In the classroom teaching, still the center into English grammar level, simple way to explain the main, there is no innovation classroom interaction patterns, not the language and communication together after school when assignments are often not binding objectives and priorities go select issues, particularly ignoring the sense of English language and Western cultural background influence students 'interest in learning the impact of English, can not really show the unique charm of English from the artistic content of English literature and other aspects, these are the teachers' comprehensive quality, including professional competence, teaching concepts are closely related. In order to improve the quality of teachers, promote innovation reform process, but also the skills of teachers and teaching performance assessment review.

We know that teaching evaluation of teaching activities to the end of a link, is both a way to detect the effect of their teachers, but also an important means of inspection visits to student learning effect. By harvesting and carry out teaching evaluation feedback, can be targeted to adjust teaching methods to ensure the quality and effectiveness of English. English class since the school opened, and other disciplines, as it means to examine test papers have been quite complete, there are a large University English Test (forty-six, etc.), there are some tests in school organizations. Can not deny the role of the assessment examined the papers, but after all, is an English language course, simply by writing exhibits students' English ability is not enough. If you do not make it to be innovative diversification, improve the evaluation mechanism, to assess neglected communicative English, eventually causing students to learn English in an isolated state social dilemma.

\section{Implementation Strategy of Innovative College English Reform}

Enrich the curriculum of foreign students flexible communication chips. Because the economic development of the open, "Gaofendineng" or "heavy paper light processing" knowledge structure can not be adapt to the development of the times. So while the content of college English teaching should pay attention to follow the pace for innovative choreography, such as can be screened from the all-encompassing American and British Foreign newspapers and magazines can meet the needs of everyday use of language, but also to stimulate students' interest in learning, humanity and strong at the same time without losing modern and contemporary beauty of the text as text works to broaden the horizons of students, so that students learn in the classroom is limited, understanding the essence of outstanding foreign culture, and then make their own sentiments and ideas nurtured obtained [2]. But we also need to add some more knowledge extension class. Appropriate universal interdisciplinary subjects and relevant knowledge, such as economy, science and technology, science and engineering or technical profile. In the teaching objectives, in addition to meet basic college English teaching objectives, should be combined with the results of market considerations, stratified by grade of gradient curriculum. Increase the proportion of bilingual curriculum and teaching in the field of oral expression. In addition to these, students should also be combined with 
the specific circumstances, such as after the student intends to engage in business class, we should pay attention to apply their knowledge. For students who aspire to studies, it is necessary to use the ability of professional literature and articles designed from the start to develop their search, focus on strengthening academic knowledge.

The ancients once said famously, well illustrates the impact of teaching art: "Good teaching, academics and Yi Gong times; those poor teaching, learning and labor power and a half." Originally a student to enjoy the university classroom to absorb extensive knowledge of marine, is to improve their comprehensive quality golden hall, the university is a combination of English and humanities disciplines context. As a classroom teacher's guide and organizers need to adapt to the times on the basis of the development of innovative concepts on the basis of their teaching methods and attitudes up some introspection and innovation.

So there are improvements in the following areas: first, the innovation of their teaching philosophy to the times. Strong response to the national call for the application of talent, truly student-centered, establish with the "flipped classroom" or "micro-classroom", "Mu class" teaching ideas, develop their own sensitivity to Western culture, led the students English affection. As introduced in this session, introduce more background interspersed with Western customs, so that students improve their English reading and English works of the level of appreciation in a relaxed atmosphere. Second, their innovative teaching methods. So that teaching becomes diverse and enriched. Participate in training to improve their operations and multimedia courseware selection of video production skills, the real from the students' interests and personality departure, encourage students to think boldly. Around the "student-centered" in the theme, the classroom truly become actively involved in students the knowledge and language practice places. Engage in more outreach activities of oral communication or exchange sessions, organizing scenario simulation training, debates, speech contests, so that the curricular unit students hear English, English, English translation and other comprehensive language training and capacity increase. Third, the "Give a man a fish, as delegate to fish." Guide students out of class combination, give full play the role of libraries, library and the Internet, to encourage more students to extracurricular reading relevant books, Thinking with multi-view television and video-related, conditional, it can also encourage students to dialogue with students exchange, or to foreigners relatively concentrated areas, to create the English corner. Actively seek learning opportunities for students to find their own way to learn English.

Teaching methods and innovative teaching philosophy must also have an impact on the teaching reform of the rating mechanism. Combination of the above drawbacks of teaching evaluation system to analyze and adverse consequences caused to the students, you can model evaluation mechanism innovation as follows: First, in the conventional written test in speaking and writing sections of these topics proportion, as in theory on the basis of students' knowledge intensive; secondly, rich classroom assessment form. It is generally used in the past the teacher evaluation of students one-way mode, we can consider teachers and peer assessment, peer assessment and other life and a variety of evaluation methods, both to achieve both teaching and learning, but also to supervise complement each other and promote each other, to improve their English. Real incentive to learn the students' interest, rather than allowing students to produce too much pressure and fear psychology. Students can also establish assessment files, file a detailed record of students usually embodied in classroom situations, attendance, task completion, and expand the use of extra-curricular learning and other relevant circumstances, at the end of the evaluation, considering these archives recording information in accordance with a certain proportion of assessment, and thus the overall quality of students comprehensive evaluation [3]. In addition, the Internet thinking applied to the evaluation mechanism, the establishment of online evaluation mechanism remote evaluation.

\section{Conclusion}

In summary, under the background of international development, innovation and reform of college English teaching should focus on improving the students' ability to use. Completely change before a 
single teaching mode. To reconcile the students' interest and respect for the personality development of students, but also pay attention to their own culture Students have read say dictation reserves knowledge and communicative combine. Of course, innovative teaching particular attention to handle the relationship between inheritance and carry forward, on the one hand to boldly irrational mode of teaching to say "no"; on the other hand can not blindly follow the trend, keep their eyes open, rational dialectical thinking innovation. This requires each university educators constantly innovative teaching practices to enrich the experience.

\section{Acknowledgements}

Fund project: the phased research achievement of "Research on College English Teaching Reform Under the Guidance of the New Guidelines for College English Teaching-Taking the Example of Xi'an International University" (Project no::2015B11), subsidized by 2015 Special Fund for Research on Education, Teaching and Reform of Xi'an International University

\section{References}

[1] Gu Shimin. Course in College Students' Autonomous Learning promote research [D]. Shanghai International Studies University, 2013.

[2] Li Xiaoxiang. Innovative thinking and English proficiency training - the exploration of English teaching model research universities, Southeast University [J]. Chinese university teaching, 2011,11: 29-32...

[3] Xie Yi. innovative research local university in College English Teaching [J]. Snow lotus, 2015,36: $71+73$. 